\title{
Loneliness and social behaviors in a virtual social environment
}

Maike Luhmann ${ }^{1}$, Felix Schönbrodt ${ }^{2}$, Louise C. Hawkley ${ }^{3}$, \& John T. Cacioppo ${ }^{4}$

${ }^{1}$ Department of Psychology, University of Illinois at Chicago, Chicago, IL, USA

${ }^{2}$ Department of Psychology, Ludwig-Maximilians-Universität München, Munich, Germany

${ }^{3}$ NORC at the University of Chicago, Chicago, IL, USA

${ }^{4}$ Department of Psychology and Center for Cognitive and Social Neuroscience, University of Chicago, Chicago, IL, USA

in press in Cognition and Emotion

May 5, 2014

Corresponding author: Maike Luhmann, Department of Psychology, University of Illinois at Chicago, 1007 W. Harrison Street, Chicago, IL, USA, luhmann@uic.edu. 


\begin{abstract}
Feeling lonely motivates people to reconnect with others, but it can also trigger a vicious cycle of cognitions and behaviors that reinforces their loneliness. In this study, we examined the behavioral consequences of loneliness in a virtual social environment. A total of 176 participants navigated a character (protagonist) through a two-dimensional browser game and rated the character's loneliness multiple times during the game. In the first part of the game, another character is introduced as the protagonist's spouse. At one point, the spouse leaves for an undetermined period of time but later returns. Immediately before this separation, higher ascribed loneliness of the protagonist was associated with more frequent interactions with the spouse. After the reunion, however, higher ascribed loneliness was associated with less frequent interactions with the spouse. Ascribed loneliness was not significantly related to the frequency of interactions with others nor to the frequency of solitary activities. These patterns held after controlling for ascribed positive affect. Participants' levels of loneliness were related to the level of ascribed loneliness only when the spouse was present but not when the spouse was absent. In sum, these findings suggest that the conditions that trigger the vicious cycle of loneliness are person-specific and situation-specific.
\end{abstract}

Keywords: loneliness, perceived social isolation, virtual social environment 


\section{Loneliness and social behaviors in a virtual social environment}

Social connections are essential for human survival and thriving (Cacioppo \& Patrick, 2008; Harlow, 1958). When social connections are severed, people tend to feel lonely (Peplau \& Perlman, 1982). Feelings of loneliness, in turn, foster attempts to reconnect or forge new connections (Cacioppo \& Patrick, 2008; Weiss, 1973). Ironically, however, feelings of loneliness can also increase the risk for rejection and loneliness through a vicious cycle of maladaptive perceptions, cognitions, and behaviors (Cacioppo \& Hawkley, 2005, 2009; Duck, Pond, \& Leatham, 1994). For instance, feelings of loneliness are accompanied by a heightened vigilance for social threat (van Roekel et al., 2013), heightened distrust of others (Rotenberg, 1994), and heightened expectations for rejection (Downey, Freitas, Michaelis, \& Khouri, 1998). Higher loneliness is also associated with more negative perceptions of social interactions in general (Hawkley, Burleson, Berntson, \& Cacioppo, 2003) and of close others in particular (Tsai \& Reis, 2009). Moreover, loneliness and social rejection have been associated with a host of maladaptive behaviors such as increased aggressive behaviors towards the offending party (Twenge, Baumeister, Tice, \& Stucke, 2001), decreased approach-oriented social strategies (Nurmi \& Salmela-Aro, 1997), and decreased prosocial behaviors (Twenge, Baumeister, DeWall, Ciarocco, $\&$ Bartels, 2007). All of these behaviors have the potential to diminish the quality of interactions and increase loneliness (e.g., Downey et al., 1998; Nurmi, Toivonen, Salmela-Aro, \& Eronen, 1996).

In sum, feelings of loneliness can have adaptive behavioral consequences (i.e., reconnecting with others) as well as maladaptive behavioral consequences (i.e., withdrawing 
from or punishing others). However, the specific circumstances that lead lonely people to act adaptively versus maladaptively are largely unknown. In this paper, we assume that maladaptive behaviors are most likely to arise after the temporary severing of an established social connection through physical separation. A robust finding in attachment research is that individuals with an avoidant attachment style respond to such a separation through avoidant or aggressive behaviors towards the offending party (Ainsworth, Blehar, Waters, \& Wall, 1978; Mikulincer \& Florian, 1998). Attachment processes are thought to underlie one of the phenotypic facets of loneliness (Cacioppo \& Cacioppo, 2012), a facet that is associated with a significant other (spouse) in adults (Hawkley, Browne, \& Cacioppo, 2005). We therefore expect a similar reaction among those who respond to separation with increased expressions of loneliness. We hypothesize that while higher loneliness before the separation is associated with more frequent social interactions (Hypothesis 1a), higher loneliness after the separation is associated with less frequent social interaction behaviors overall and more negative behaviors toward the offending party in particular (cf. Twenge et al., 2001) (Hypothesis 1b).

We investigate this hypothesis in the virtual social environment (VSE) Simoland (Schönbrodt \& Asendorpf, 2011a, 2011b). In VSEs, participants control a virtual character (protagonist) who can engage in different social and non-social behaviors. VSEs are particularly useful to study social interactions because they combine the advantages of experimental laboratory studies (i.e., standardized social environment) with the strengths of non-experimental field studies (i.e., the possibility to engage in a wide range of social interactions with multiple partners). Social relationships are formed during the game and are therefore initially objectively comparable across participants (but of course, participants can differ in their perceptions of these relationships due to personality differences). These relationships can be made meaningful by 
imposing certain roles, for instance by introducing another character as the significant other. In the VSE used here, a social connection is first established by introducing another character as the protagonist's partner and then temporarily severed by separating the protagonist and the partner (for details, see below).

In VSEs, the participants might choose behaviors that they consider the typical response to these kinds of situations or they might choose those behaviors they would show if they experienced a similar situation in real life. To test the latter mechanism, we examined whether the participants' levels of loneliness (subject loneliness) are related to how they rate their protagonists' feelings of loneliness. We hypothesized that participants high in loneliness generally ascribe higher levels of loneliness to their protagonist (Hypothesis 2). Furthermore, we expected to see the weakest association during the separation from the partner (Hypothesis $3 a$ ). Feeling lonely is a normal reaction to social isolation, and ascribed loneliness should therefore be high during separation across participants. In addition, we expected to see the strongest association after the reunion with the partner such that lonely participants are more likely than non-lonely participants to continue to perceive their protagonists as lonely after the end of the objective isolation (Hypothesis 3b). 


\section{Methods}

\section{Procedure and Sample}

The final sample consisted of $N=176$ participants $^{1}(76.1 \%$ female $)$ with a mean age of 29.1 years $(S D=10.23,15$ to 60 years $)$ and was recruited by email from a panel of individuals interested in participating in studies at the Department of Psychology at the LudwigMaximilians-Universität München, Germany. The email contained a link to an online survey where participants provided informed consent and completed several baseline measures, including a measure of loneliness. The next day, they received an email with a link to the Simoland game. The one-day lag was introduced to ensure that potential affective reactions to answering questions about one's loneliness wear off before people play the game. After playing the game for 15 minutes, the participants completed additional measures of their loneliness and personality (not used here) and answered questions about the game itself. Subject loneliness was measured twice to test whether playing Simoland leads to any mean-level changes in loneliness; however, this was not the case, $t(175)=0.73, p=.468$.

\section{The VSE "Simoland"}

The VSE Simoland (Schönbrodt \& Asendorpf, 2011a, 2011b) is a simple, twodimensional browser game that is inhabited by several autonomous agents. These agents are displayed as cartoon-like round or rectangular creatures, which can express several basic emotions and autonomously engage in solitary behaviors or social interactions. Despite their

\footnotetext{
${ }^{1}$ In the absence of prior similar studies, we aimed at a sample size of $N=200$ that is sufficient to detect moderate effect sizes. Of initially 211 participants, 35 only completed the baseline survey but did not play the Simoland game and were therefore not included in the final sample.
} 
simple appearance, it was taken care that the agents behave and react in a psychologically believable way (Schönbrodt \& Asendorpf, 2011a). Participants of the study can control one of the characters (henceforward called protagonist), whose gender is matched to that of the participant. The other characters cannot be controlled by the participant, but rather behave autonomously and contingent on the actions of the protagonist (positive behaviors are reciprocated with positive behaviors; negative behaviors are reciprocated with negative behaviors). Another character of the opposite gender is explicitly introduced as the protagonist's partner (henceforth called virtual spouse). Participants were instructed to freely play the game, without any goals that had to be accomplished. In order to increase the social significance of the behavioral choices, it was emphasized that every choice participants made had an effect on the mood and the behavior of the other characters and would affect their relationship.

Anytime during the game, the participant can choose from a list of behaviors for the protagonist, including solitary activities (e.g., eating, painting) and, if other characters are present, social interactions (e.g., talking, cuddling). In this study, we examined the frequency of solitary activities, the overall frequency of protagonist-initiated interactions with the spouse, the frequency of affectionate interactions with the spouse (e.g., kissing), the frequency of provocative behaviors toward the spouse (e.g., fighting, cheating), and the frequency of protagonist-initiated interactions with other characters (see Table S1 for a complete list of all analyzed behaviors).

The game proceeds in a sequence of six scenes (Figure 1). Within each scene, the VSE is an open world where participants can freely choose where their protagonist should go and what it should do. Several actions can be chosen sequentially at any point during the game, where the number of performed actions is only limited by the time limits of the specific scene (for more 
details on the game, see Schönbrodt and Asendorpf, 2011b). At specific time points during the game, however, pre-defined scenes are staged. At first, the protagonist is alone (Intro scene). Next, the virtual spouse (Dyad scene) and other characters (All Together scene) are introduced. At one point, the virtual spouse leaves for an unknown period of time because of a death in the family (Separation scene). A few minutes later, the spouse returns (Reunion scene). The game ends with the final Outro scene. This setup allows us to examine the relationship between the protagonist's ascribed loneliness and behaviors before and after the severing of an important social connection.

Five times, the game is interrupted and the participants are asked to rate their protagonist's emotions (ascribed emotions), including the protagonist's loneliness (ascribed loneliness). These ratings were timed to occur shortly before or after a relevant event: (1) at the end of the intro scene, (2) at the end of the all-together scene, (3) immediately after the separation, (4) immediately after the reunion, and (5) at the beginning of the outro scene (Figure 1). We expect that higher ascribed loneliness at the end of the intro scene is associated with more frequent social interactions with the spouse and with others during the all-together scene (adaptive response; Hypothesis 1a). In contrast, we expect that higher ascribed loneliness measured immediately after the reunion is associated with less frequent interactions with the spouse overall and more frequent provocative behaviors towards the spouse during the reunion scene (maladaptive response; Hypothesis $1 \mathrm{~b}$ ).

\section{Measures}

Subject loneliness was measured with the German translation of the revised 20-item UCLA Loneliness Scale (Döring \& Bortz, 1993; English version: Russell, Peplau, \& Cutrona, 
1980) with $\alpha=.92$ and a one-day retest stability of $r=.92$. The items were answered on a 5point scale ranging from 0 (does not apply at all) to 4 (applies completely) and averaged such that higher scores indicate higher levels of loneliness. On average, participants in this sample reported low loneliness scores with $M=0.92(S D=0.59, M d=0.8)$. Subject loneliness was measured twice (see above) but only the first measurement occasion on the day before participants played the game was used in the present analyses.

Ascribed emotions of the protagonist were measured with seven bipolar items with 7point scales. The items were presented in a pop-up window during the game. The item with the poles secure/connected (geborgen) vs. lonely (einsam) was used as a measure of ascribed loneliness with higher scores reflecting higher ascribed loneliness. The remaining six items (e.g., sad vs. joyful; for a complete list, see Schönbrodt \& Asendorpf, 2012) were aggregated to form an index of ascribed positive affect (PA).

\section{Data analysis}

We used a path model that allowed us to examine the lagged associations between ascribed loneliness and social behaviors (e.g., the effect of ascribed loneliness immediately after the reunion on the frequency of interactions with the spouse during the remainder of the reunion scene) as well as autoregressive associations which reflect the rank-order stability of each variable (Figure 1). This model was fitted separately for each of the five behavioral variables and extended to include variables such as PA. Scenes in which few or no behaviors of the behavioral outcome were observed were excluded from the respective path model. For example, the average frequency of interactions with the spouse during the separation (e.g., thinking about the spouse) was close to zero (see Table 1). This variable was therefore excluded from the path model, 
meaning that none of the associated paths was modeled (for details, see caption to Figure 1). The analyses were conducted in $\mathrm{R}$ (R Development Core Team, 2011) using the lavaan package (Rosseel, 2012).

\section{Results}

\section{Descriptive results}

Descriptive statistics are reported in Table 1 (for correlations, see Tables S2 and S3). The mean levels of ascribed loneliness and the five behavioral variables across the different scenes were similar to previous studies using Simoland (Schönbrodt \& Asendorpf, 2012). These statistics were not of primary interest for the present paper and are therefore not discussed in detail. Note, however, that ascribed loneliness was higher during the separation scene and during the intro scene and lower during those scenes when others were present, suggesting that just as in real life, the participants ascribed higher levels of loneliness during times of objective isolation.

\section{Ascribed emotions and social interactions}

To test the association between ascribed loneliness and subsequent social behaviors, we examined the lagged effects of ascribed loneliness on social behaviors (all Model 1's in Table 2). For solitary activities and interactions with others, these effects were non-significant. For the three spouse-directed interaction variables, however, several path coefficients reached significance. Higher ascribed loneliness at the end of the intro scene was associated with more frequent interactions with the spouse in general and more affectionate behaviors in particular during the all-together scene (path $c_{2}$ ), supporting the notion that loneliness motivates people to connect with others (Hypothesis 1a). After the separation, however, the pattern reversed: Higher 
ascribed loneliness immediately after the reunion was associated with less frequent interactions with the spouse, less frequent affectionate behaviors, and more frequent provocative behaviors during the subsequent reunion scene (path $c_{4}$ ). This finding is consistent with the vicious cycle model according to which people high in loneliness tend to withdraw from others (Hypothesis 1b). In sum, these findings show that feelings of loneliness can trigger both adaptive and maladaptive social behaviors, depending on the specific situation. However, this effect seems to be limited to the virtual spouse as ascribed loneliness was not significantly related to interactions with others nor to solitary activities in any of the scenes.

Regarding the association between the frequency of social interactions and subsequent ascribed loneliness, significant effects were found for only two behavioral variables. Specifically, a higher frequency of affectionate behaviors during the all-together scene was associated with lower ascribed loneliness at the end of this scene (path $d_{1}$ ) and with higher ascribed loneliness immediately after the separation (path $d_{2}$ ). Similarly, a higher frequency of provocative behaviors during the all-together scene was significantly associated with higher ascribed loneliness at the end of the all-together scene (path $\left.d_{1}\right)$ and marginally $(p=.053)$ associated with higher ascribed loneliness immediately after reunion (path $d_{2}$ ).

In an additional analysis, we added PA to the path model to examine whether the significant lagged effects of ascribed loneliness are unique to loneliness or due to a more general effect of ascribed PA (all Model 2's in Table 2). The associations between ascribed loneliness at the end of the intro scene and the three spouse-directed behaviors during the all-together scene (path $c_{2}$ ) as well as the associations between ascribed loneliness immediately after the reunion and the three spouse-directed behaviors during the subsequent reunion scene (path $c_{4}$ ) were unchanged when ascribed PA was controlled. Moreover, ascribed PA was not significantly 
associated with the behavioral variables during these scenes. However, adding ascribed PA to the model did change the results for the outro scene. Recall that in this scene ascribed loneliness was not significantly associated with any of the three spouse-directed interaction variables in the model above. After adding ascribed PA to the model, higher ascribed loneliness at the beginning of the outro scene was associated with an increased frequency of affectionate behaviors (i.e., with adaptive behaviors) and higher ascribed PA was associated with an increased frequency of affectionate behaviors during the outro scene (path $c_{5}$ ). This pattern was similar for general interactions with the spouse, but the coefficient of ascribed loneliness was only marginally significant $(p=.069)$. Finally, neither ascribed loneliness nor ascribed PA were associated with the frequency of provocative behaviors during the outro scene.

In sum, ascribed loneliness (but not ascribed PA) was associated with adaptive behaviors before the separation and with maladaptive behaviors after the separation, suggesting that the consequences of loneliness are situation-specific and person-specific.

\section{Subject loneliness}

Consistent with Hypothesis 2, subject loneliness (measured on the previous day) was generally positively associated with ascribed loneliness if all measures of ascribed loneliness were aggregated $(r=.32, p=.002)$. However, the strength of this association varied between the five scenes. Subject loneliness and ascribed loneliness were significantly correlated during those scenes where the spouse was present, with correlation coefficients of $r=.26$, (all together), $r=$ .32 (reunion), and $r=.38$ (outro), all $p s<.001$, but not during those scenes when the spouse was absent, $r=.03$ (alone) and $r=.02$ (separation), all $p s>.05$. These findings are consistent with 
our hypothesis that the correlation is weaker during separation (Hypothesis 3a) and stronger after the reunion (Hypothesis 3b).

To test whether subject loneliness might explain the lagged associations between ascribed loneliness and spouse-directed behaviors found above, we added subject loneliness as a predictor of all variables in the path model. ${ }^{2}$ As would be expected based on the correlation coefficients, subject loneliness was positively associated with ascribed loneliness during the all-together scene, the reunion scene, and the outro scene. However, no significant associations between subject loneliness and specific behaviors were found, and the lagged effects of ascribed loneliness on social interaction behaviors reported above remained significant even after controlling for subject loneliness.

\section{Discussion}

Feeling lonely can motivate people to actively connect with others, but it can also trigger a vicious cycle of cognitions and behaviors that reinforce their loneliness (Cacioppo \& Hawkley, 2009). Using a VSE paradigm, we examined the conditions that produce these divergent behavioral responses. Before the separation, higher ascribed loneliness was associated with a greater frequency of social interactions with the spouse. After the temporary separation from the spouse, however, this association was reversed. Higher ascribed loneliness immediately after the reunion was associated with less frequent interactions with the spouse overall and more provocative and less affectionate behaviors towards the spouse in particular. These effects are unique to ascribed loneliness as they hold even after controlling for ascribed PA. In contrast, ascribed loneliness was unrelated to the frequency of social interactions with other (non-spousal)

\footnotetext{
${ }^{2}$ Results are available from the first author upon request.
} 
characters and with solitary activities, meaning that while ascribed loneliness does not generally increase the frequency of maladaptive behaviors, it also does not lead to compensatory behaviors such that others are sought out more frequently. In sum, these findings suggest that the cognitions and behaviors that characterize the vicious cycle of loneliness are situation-specific and person-specific.

Previous accounts are surprisingly mute on the situational circumstances under which loneliness leads to adaptive versus maladaptive behaviors. Our study suggests that adaptive responses are more common until a specific situation triggers the vicious cycle. Here, this trigger was the separation from the spouse. This separation was entirely uncontrollable for the protagonist as it was initiated by the spouse and of unknown duration. It should be emphasized that during the separation, the average level of ascribed loneliness was very high and varied minimally between participants, indicating that loneliness is a "normal" reaction to separation. It is only after the reunion with the spouse that differences in ascribed loneliness re-emerge and are associated with differences in the frequency of social interactions. The Simoland paradigm did not allow us to study the processes that link these two variables, but based on other research, we can speculate that those who ascribed higher levels of loneliness after the separation were more likely to construe the separation as a willful rejection that could re-occur at any moment, and hence increase their expectations of rejection and increase their distrust of the spouse (Downey et al., 1998; Rotenberg, 1994). In addition, the uncontrollability of the separation might have increased the perception of lack of control, which has been identified as a source of loneliness (Newall et al., 2009). These processes need to be examined more explicitly in future studies.

There are at least two (not mutually exclusive) explanations for the person-specificity of the vicious cycle. First, this finding could be due to the perceived closeness between the 
protagonist and the spouse, suggesting that maladaptive behaviors are more likely towards close others than towards more distant acquaintances (Tsai \& Reis, 2009). Second, maladaptive responses could be specific to those who caused the feelings of loneliness in the first place (Twenge et al., 2001). Indeed, the parting of the spouse leads to higher levels of ascribed loneliness, and it is the spouse and not the other characters who are "punished" upon the return. To disentangle these alternative explanations of the person-specificity of the vicious cycle, future studies should vary these different explanatory factors more systematically.

Up to this point, we have discussed the patterns observed in Simoland as if they could be generalized directly to real life, but we do not know for certain if this is the case. It is possible that the participants ascribe the same emotions and engage in the same behaviors in Simoland as they would in real life. However, it is also possible that the reported emotions and shown behaviors reflect how participants expect others to typically behave in such situations. Past research (Schönbrodt \& Asendorpf, 2012) suggested that people playing Simoland act similarly to how they would in real life, and they project how they would feel in similar situations upon their protagonists. Similarly, in this study, subject loneliness was correlated with ascribed loneliness in those scenes when the spouse was present, suggesting that the participants used their own level of loneliness as an anchor to rate their protagonists' loneliness. We do not know, however, if the behaviors that the participants chose for their characters are equally indicative of how they would behave in similar situations as we did not have behavioral data of the participants. Hence, while our and a previous study suggest that VSEs reflect real-life 
experiences and behaviors ${ }^{3}$, it is still possible that the responses observed in Simoland are also influenced by people's ideas about what is the normative reaction in these kinds of situations.

It is also noteworthy that most of the significant effects were found for variables measured during those scenes when the spouse was present but not for variables measured when the spouse was absent (e.g., association between ascribed loneliness and frequency of interactions with the spouse, association between subject loneliness and ascribed loneliness). This pattern of results is consistent with the distinction between strong and weak situations (Cooper \& Withey, 2009; Mischel, 1977). Strong situations are characterized by clear behavioral demands and therefore elicit similar responses across all individuals. In Simoland, the scenes when the spouse is absent appear to be strong situations as the level of loneliness is high on average and varies minimally across individuals. Weak situations, in contrast, do not have clear behavioral demands and therefore are more likely to give rise to observable individual differences. In Simoland, the scenes when the spouse is present appear to be weak situations as we observe significant associations between subject loneliness and ascribed loneliness and between ascribed loneliness and the frequency of social interactions with the spouse.

A few limitations need to be mentioned. First, while the cross-lagged panel analyses incorporated the temporal dimension and therefore lend credence to the directional (i.e., causal) hypotheses, our study design was nevertheless correlational and thus precludes any strong causal inferences. Second, to minimize interruptions during the game, ascribed loneliness was measured using a single item which possibly is less reliable than multi-item measures. Third, as discussed above, our study design is not suitable to determine whether the participants project their own

\footnotetext{
${ }^{3}$ This conclusion is also backed by the responses to eight items designed to measure the credibility of the game (see Table S4).
} 
imagined experiences and behaviors upon their character or whether they report emotions and choose behaviors according to what they consider the normal response to the situations encountered during the game. Fourth, the results should not be generalized to the total population as our sample was dominated by young women and restricted to individuals with at least some internet routine. Furthermore, few participants were high in loneliness, as indicated by the low mean of subject loneliness. To investigate whether individuals high vs. low in loneliness differ systematically in how they navigate VSEs, future studies should replicate this study with a sample of individuals high in loneliness. Finally, Simoland was designed to study attachment rather than loneliness and therefore did not allow us to test each step of the vicious cycle. It might be worthwhile to develop a VSE that includes the measurement of perceptions and cognitions to allow a test of the full vicious cycle model.

In summary, our study has qualified the vicious cycle model by showing that maladaptive responses to loneliness are person-specific (here: spouse) and situation-specific (here: physical separation). Future research can test these revisions to the vicious cycle model and identify yet additional individuals (e.g., close friends and family members or members of a larger collective group) and situations (e.g., conflicts or perceived lack of attention from the other party) that may cause lonely people to act in maladaptive ways toward others. 


\section{References}

Ainsworth, M., Blehar, M. C., Waters, E., \& Wall, S. (1978). Patterns of attachment: A psychological study of the strange situation. Hillsdale, NJ: Erlbaum.

Cacioppo, J. T., \& Cacioppo, S. (2012). The phenotype of loneliness. European Journal of Developmental Psychology, 9(4), 446-452. doi: 10.1080/17405629.2012.690510

Cacioppo, J. T., \& Hawkley, L. C. (2005). People thinking about people: The vicious cycle of being a social outcast in one's own mind. In K. D. Williams, J. P. Forgas \& W. von Hippel (Eds.), The social outcast: Ostracism, social exclusion, rejection, and bullying (pp. 91-108). New York: Psychology Press.

Cacioppo, J. T., \& Hawkley, L. C. (2009). Perceived social isolation and cognition. Trends in Cognitive Sciences, 13(10), 447-454.

Cacioppo, J. T., \& Patrick, B. (2008). Loneliness: Human nature and the need for social connection. New York: Norton.

Cooper, W. H., \& Withey, M. J. (2009). The strong situation hypothesis. Personality and Social Psychology Review, 13(1), 62-72. doi: 10.1177/1088868308329378

Downey, G., Freitas, A. L., Michaelis, B., \& Khouri, H. (1998). The self-fulfilling prophecy in close relationships: Rejection sensitivity and rejection by romantic partners. Journal of Personality and Social Psychology, 75(2), 545-560. 
Duck, S., Pond, K., \& Leatham, G. (1994). Loneliness and the evaluation of relational events. Journal of Social and Personal Relationships, 11(2), 253-276. doi: http://dx.doi.org/10.1177/0265407594112006

Döring, N., \& Bortz, J. (1993). Psychometrische Einsamkeitsforschung: Deutsche Neukonstruktion der UCLA Loneliness Scale. [Psychometric research on loneliness: A new German version of the University of California at Los Angeles (UCLA) Loneliness Scale.]. Diagnostica, 39(3), 224-239.

Harlow, H. F. (1958). The nature of love. American Psychologist, 13(12), 673-685. doi: http://dx.doi.org/10.1037/h0047884

Hawkley, L. C., Browne, M. W., \& Cacioppo, J. T. (2005). How can I connect with thee? Let me count the ways. Psychological Science, 16(10), 798-804.

Hawkley, L. C., Burleson, M. H., Berntson, G. G., \& Cacioppo, J. T. (2003). Loneliness in everyday life: Cardiovascular activity, psychosocial context, and health behaviors. Journal of Personality and Social Psychology, 85(1), 105-120.

Mikulincer, M., \& Florian, V. (1998). The relationship between adult attachment styles and emotional and cognitive reactions to stressful events. In J. A. Simpson \& W. S. Rholes (Eds.), Attachment theory and close relationships (pp. 143-165). New York: Guilford Press.

Mischel, W. (1977). The interaction of person and situation. In D. Magnusson \& N. S. Endler (Eds.), Personality at the crossroads: Current issues in interactional psychology (pp. 333-352). Hillsdale, NJ: Erlbaum. 
Newall, N. E., Chipperfield, J. G., Clifton, R. A., Perry, R. P., Swift, A. U., \& Ruthig, J. C. (2009). Causal beliefs, social participation, and loneliness among older adults: A longitudinal study. Journal of Social and Personal Relationships, 26(2-3), 273-290.

Nurmi, J.-E., \& Salmela-Aro, K. (1997). Social strategies and loneliness: A prospective study. Personality and Individual Differences, 23(2), 205-215. doi: http://dx.doi.org/10.1016/S0191-8869(97)00039-1

Nurmi, J.-E., Toivonen, S., Salmela-Aro, K., \& Eronen, S. (1996). Optimistic, approachoriented, and avoidance strategies in social situations: Three studies on loneliness and peer relationships. European Journal of Personality, 10(3), 201-219. doi: http://dx.doi.org/10.1002/(SICI)1099-0984(199609)10:3<201::AID-PER257>3.0.CO;2

Peplau, L. A., \& Perlman, D. (Eds.). (1982). Loneliness: A sourcebook of current theory, research, and therapy. New York: Wiley.

R Development Core Team. (2011). R: A language and environment for statistical computing. Vienna, Austria: R Foundation for Statistical Computing.

Rosseel, Y. (2012). lavaan: An R package for structural equation modeling. Journal of Statistical Software, 48(2), 1-36.

Rotenberg, K. J. (1994). Loneliness and interpersonal trust. Journal of Social and Clinical Psychology, 13(2), 152-173.

Russell, D., Peplau, L. A., \& Cutrona, C. E. (1980). The revised UCLA Loneliness Scale: Concurrent and discriminant validity evidence. Journal of Personality and Social Psychology, 39(3), 472-480. doi: 10.1037/0022-3514.39.3.472 
Schönbrodt, F. D., \& Asendorpf, J. B. (2011a). The challenge of constructing psychologically believable agents. Journal of Media Psychology: Theories, Methods and Applications, 23(2), 100-107. doi: 10.1027/1864-1105/a000040

Schönbrodt, F. D., \& Asendorpf, J. B. (2011b). Virtual social environments as a tool for psychological assessment: Dynamics of interaction with a virtual spouse. Psychological Assessment, 23(1), 7-17. doi: 10.1037/a0021049

Schönbrodt, F. D., \& Asendorpf, J. B. (2012). Attachment dynamics in a virtual world. Journal of Personality, 80(2), 429-463. doi: 10.1111/j.1467-6494.2011.00736.x

Tsai, F.-F., \& Reis, H. T. (2009). Perceptions by and of lonely people in social networks. Personal Relationships, 16(2), 221-238.

Twenge, J. M., Baumeister, R. F., DeWall, C. N., Ciarocco, N. J., \& Bartels, J. M. (2007). Social exclusion decreases prosocial behavior. Journal of Personality and Social Psychology, 92(1), 56-66. doi: 10.1037/0022-3514.92.1.56

Twenge, J. M., Baumeister, R. F., Tice, D. M., \& Stucke, T. S. (2001). If you can't join them, beat them: Effects of social exclusion on aggressive behavior. Journal of Personality and Social Psychology, 81, 1058-1069. doi: 10.1037/0022-3514.81.6.1058

van Roekel, E., Goossens, L., Verhagen, M., Wouters, S., Engels, R. C. M. E., \& Scholte, R. H. J. (2013). Loneliness, affect, and adolescents' appraisals of company: An experience sampling method study. Journal of Research on Adolescence, Advance online publication. doi: 10.1111/jora.12061

Weiss, R. S. (1973). Loneliness: The experience of emotional and social isolation: Cambridge, MA, US: The MIT Press. 


\section{Tables}

Table 1. Means and standard deviations for all repeatedly measured variables

\begin{tabular}{|c|c|c|c|c|c|c|c|c|c|c|c|c|c|c|}
\hline \multirow[t]{2}{*}{ Scene } & \multicolumn{2}{|c|}{$\begin{array}{l}\text { Ascribed } \\
\text { loneliness }\end{array}$} & \multicolumn{2}{|c|}{ Ascribed PA } & \multicolumn{2}{|c|}{$\begin{array}{l}\text { Frequency of } \\
\text { interactions } \\
\text { with others }\end{array}$} & \multicolumn{2}{|c|}{$\begin{array}{l}\text { Frequency of } \\
\text { interactions } \\
\text { with spouse }\end{array}$} & \multicolumn{2}{|c|}{$\begin{array}{c}\text { Frequency of } \\
\text { affectionate } \\
\text { behaviors }\end{array}$} & \multicolumn{2}{|c|}{$\begin{array}{l}\text { Frequency of } \\
\text { provocative } \\
\text { behaviors }\end{array}$} & \multicolumn{2}{|c|}{$\begin{array}{l}\text { Frequency of } \\
\text { solitary } \\
\text { activities }\end{array}$} \\
\hline & $M$ & $S D$ & $M$ & $S D$ & $M$ & $S D$ & $M$ & $S D$ & $M$ & $S D$ & $M$ & $S D$ & $M$ & $S D$ \\
\hline Intro & 4.37 & 1.61 & 4.14 & 0.90 & & & & & & & & & 2.99 & 1.26 \\
\hline Dyad & & & & & & & 4.36 & 1.94 & 1.41 & 1.07 & 0.13 & 0.34 & 1.73 & 1.27 \\
\hline All together & 2.68 & 1.41 & 4.45 & 1.01 & 1.85 & 1.41 & 1.40 & 1.38 & 0.64 & 0.95 & 0.18 & 0.49 & 0.90 & 1.01 \\
\hline Separation & 5.46 & 1.38 & 2.68 & 0.96 & 1.89 & 1.68 & 0.01 & 0.08 & 0.01 & 0.08 & 0.09 & 0.33 & 1.70 & 1.48 \\
\hline Reunion & 2.02 & 1.19 & 4.79 & 1.08 & 1.48 & 1.73 & 4.63 & 2.29 & 2.08 & 1.55 & 0.23 & 0.68 & 1.61 & 1.42 \\
\hline Outro & 2.18 & 1.15 & 4.67 & 1.16 & 0.20 & 0.47 & 0.77 & 0.86 & 0.53 & 0.72 & 0.04 & 0.19 & 0.31 & 0.57 \\
\hline
\end{tabular}


Table 2. Path coefficients for all path models

\begin{tabular}{|c|c|c|c|c|c|c|c|c|c|c|c|c|c|c|c|c|c|c|c|c|}
\hline \multirow[t]{3}{*}{ Coefficients } & \multicolumn{4}{|c|}{$\begin{array}{c}\text { Frequency of interactions with } \\
\text { others }\end{array}$} & \multicolumn{4}{|c|}{$\begin{array}{c}\text { Frequency of interactions with } \\
\text { spouse }\end{array}$} & \multicolumn{4}{|c|}{$\begin{array}{c}\text { Frequency of affectionate } \\
\text { behaviors }\end{array}$} & \multicolumn{4}{|c|}{$\begin{array}{c}\text { Frequency of provocative } \\
\text { behaviors }\end{array}$} & \multicolumn{4}{|c|}{ Frequency of solitary activitie } \\
\hline & \multicolumn{2}{|c|}{ Model 1} & \multicolumn{2}{|c|}{ Model 2} & \multicolumn{2}{|c|}{ Model 1} & \multicolumn{2}{|c|}{ Model 2} & \multicolumn{2}{|c|}{ Model 1} & \multicolumn{2}{|c|}{ Model 2} & \multicolumn{2}{|c|}{ Model 1} & \multicolumn{2}{|c|}{ Model 2} & \multicolumn{2}{|c|}{ Model 1} & \multicolumn{2}{|c|}{ Model 2} \\
\hline & $B$ & $\beta$ & $B$ & $\beta$ & $B$ & $\beta$ & $B$ & $\beta$ & $B$ & $\beta$ & $B$ & $\beta$ & $B$ & $\beta$ & $B$ & $\beta$ & $B$ & $\beta$ & $B$ & $\beta$ \\
\hline $\begin{array}{l}\text { Autoregressive } \\
\text { effects for } \\
\text { behaviors }\end{array}$ & & & & & & & & & & & & & & & & & & & & \\
\hline$a_{1}$ & $\begin{array}{c}\mathrm{n} / \mathrm{a} \\
0.45\end{array}$ & & $\begin{array}{c}\mathrm{n} / \mathrm{a} \\
0.43\end{array}$ & & 0.07 & 0.10 & 0.09 & 0.12 & 0.07 & 0.08 & 0.07 & 0.08 & 0.10 & 0.06 & 0.12 & 0.07 & 0.11 & 0.14 & 0.11 & 0 . \\
\hline$a_{2}$ & 0.36 & 0.38 & 0.36 & 0.36 & $\begin{array}{c}\mathrm{n} / \mathrm{a} \\
0.64\end{array}$ & & $\begin{array}{c}\mathrm{n} / \mathrm{a} \\
0.68\end{array}$ & & $\begin{array}{c}\mathrm{n} / \mathrm{a} \\
0.61\end{array}$ & & $\begin{array}{c}\mathrm{n} / \mathrm{a} \\
0.61\end{array}$ & & $\mathrm{n} / \mathrm{a}$ & & $\mathrm{n} / \mathrm{a}$ & & $0.34^{*}$ & 0.22 & $0.34^{*}$ & 0.2 \\
\hline$a_{3}$ & 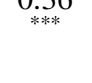 & 0.35 & 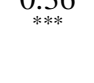 & 0.34 & $\begin{array}{l}0.04+ \\
0.13\end{array}$ & 0.41 & 0.14 & 0.44 & & 0.39 & 0.01 & 0.39 & $0.29^{* *}$ & 0.27 & $0.29^{\text {** }}$ & 0.26 & $0.15^{*}$ & 0.17 & $0.14^{*}$ & 0.1 \\
\hline$a_{4}$ & 0.00 & -0.01 & 0.00 & -0.01 & & 0.34 & & 0.35 & $0.14^{* *}$ & 0.29 & $0.13^{* *}$ & 0.27 & $0.05^{\dagger}$ & 0.15 & $0.05^{\dagger}$ & 0.16 & 0.02 & 0.05 & 0.02 & 0.0 \\
\hline \multicolumn{21}{|l|}{$\begin{array}{l}\text { Autoregressive } \\
\text { effects for } \\
\text { ascribed } \\
\text { loneliness }\end{array}$} \\
\hline$b_{1}$ & -0.04 & -0.04 & -0.04 & -0.04 & -0.03 & -0.03 & -0.02 & -0.02 & 0.01 & 0.01 & 0.01 & 0.01 & -0.03 & -0.04 & -0.03 & -0.04 & -0.04 & -0.05 & -0.04 & -0 \\
\hline$b_{2}$ & 0.09 & 0.08 & 0.09 & 0.08 & 0.09 & 0.09 & 0.09 & 0.09 & 0.14 & 0.13 & 0.14 & 0.13 & 0.05 & 0.05 & 0.05 & 0.05 & 0.08 & 0.07 & 0.08 & 0. \\
\hline$b_{3}$ & $\begin{array}{l}0.04 \\
0.51\end{array}$ & 0.04 & $\begin{array}{l}0.04 \\
0.51\end{array}$ & 0.04 & $\begin{array}{l}0.03 \\
0.47\end{array}$ & 0.04 & 0.04 & 0.05 & $\begin{array}{l}0.03 \\
0.47\end{array}$ & 0.03 & 0.03 & 0.03 & $\begin{array}{l}0.03 \\
0.48\end{array}$ & 0.03 & 0.03 & 0.03 & $\begin{array}{l}0.04 \\
0.49\end{array}$ & 0.05 & $\begin{array}{l}0.04 \\
0.49\end{array}$ & 0.0 \\
\hline$b_{4}$ & $* * * *$ & 0.52 & & 0.52 & & 0.47 & 0.04 & 0.05 & & 0.48 & 0.03 & 0.03 & 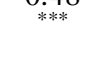 & 0.49 & 0.03 & 0.03 & U.43 & 0.50 & ${ }_{* * *}^{.43}$ & 0.5 \\
\hline \multicolumn{21}{|l|}{$\begin{array}{l}\text { Lagged effects } \\
\text { of ascribed } \\
\text { loneliness on } \\
\text { behaviors }\end{array}$} \\
\hline$c_{1}$ & $\mathrm{n} / \mathrm{a}$ & & $\mathrm{n} / \mathrm{a}$ & & $0.27^{*}$ & 0.21 & $0.25^{*}$ & 0.20 & $\begin{array}{l}0.05 \\
0.19\end{array}$ & 0.08 & 0.07 & 0.10 & 0.00 & -0.01 & -0.01 & -0.06 & 0.06 & 0.07 & 0.06 & 0 . \\
\hline$c_{2}$ & 0.10 & 0.10 & 0.13 & 0.14 & $0.25^{* *}$ & 0.29 & $0.25^{* *}$ & 0.27 & & 0.31 & $0.18^{* *}$ & 0.29 & -0.01 & -0.04 & 0.00 & 0.00 & -0.02 & -0.04 & -0.05 & -0 . \\
\hline$c_{3}$ & 0.00 & 0.00 & -0.11 & -0.09 & $\begin{array}{c}\mathrm{n} / \mathrm{a} \\
-0.53\end{array}$ & & $\begin{array}{c}\mathrm{n} / \mathrm{a} \\
-0.56\end{array}$ & & $\begin{array}{c}\mathrm{n} / \mathrm{a} \\
-\end{array}$ & & $\begin{array}{c}\mathrm{n} / \mathrm{a} \\
-\end{array}$ & & $\mathrm{n} / \mathrm{a}$ & & $\mathrm{n} / \mathrm{a}$ & & 0.01 & 0.01 & 0.03 & 0. \\
\hline$c_{4}$ & 0.18 & 0.12 & $0.28^{*}$ & 0.18 & & -0.28 & & -0.30 & $0.32^{* *}$ & -0.24 & $0.29^{* *}$ & -0.23 & $0.11^{*}$ & 0.21 & $0.13^{* *}$ & 0.25 & -0.05 & -0.05 & 0.10 & 0. \\
\hline
\end{tabular}




\begin{tabular}{|c|c|c|c|c|c|c|c|c|c|c|c|c|c|c|c|c|c|c|c|c|}
\hline \multirow[t]{3}{*}{ Coefficients } & \multicolumn{4}{|c|}{$\begin{array}{c}\text { Frequency of interactions with } \\
\text { others }\end{array}$} & \multicolumn{4}{|c|}{$\begin{array}{c}\text { Frequency of interactions with } \\
\text { spouse }\end{array}$} & \multicolumn{4}{|c|}{$\begin{array}{c}\text { Frequency of affectionate } \\
\text { behaviors }\end{array}$} & \multicolumn{4}{|c|}{$\begin{array}{c}\text { Frequency of provocative } \\
\text { behaviors }\end{array}$} & \multicolumn{4}{|c|}{ Frequency of solitary activities } \\
\hline & \multicolumn{2}{|c|}{ Model 1} & \multicolumn{2}{|c|}{ Model 2} & \multicolumn{2}{|c|}{ Model 1} & \multicolumn{2}{|c|}{ Model 2} & \multicolumn{2}{|c|}{ Model 1} & \multicolumn{2}{|c|}{ Model 2} & \multicolumn{2}{|c|}{ Model 1} & \multicolumn{2}{|c|}{ Model 2} & \multicolumn{2}{|c|}{ Model 1} & \multicolumn{2}{|c|}{ Model 2} \\
\hline & $B$ & $\beta$ & $B$ & $\beta$ & $B$ & $\beta$ & $B$ & $\beta$ & $B$ & $\beta$ & $B$ & $\beta$ & $B$ & $\beta$ & $B$ & $\beta$ & $B$ & $\beta$ & $B$ & $\beta$ \\
\hline$c_{5}$ & -0.04 & -0.11 & -0.01 & -0.02 & -0.01 & -0.02 & $0.11^{\dagger}$ & 0.15 & -0.01 & -0.01 & $0.13^{*}$ & 0.20 & -0.01 & -0.06 & -0.02 & -0.13 & $-0.07^{\dagger}$ & -0.15 & -0.18 & -0.33 \\
\hline \multicolumn{21}{|l|}{$\begin{array}{l}\text { Lagged effects } \\
\text { of behaviors on } \\
\text { ascribed } \\
\text { loneliness }\end{array}$} \\
\hline$d_{1}$ & -0.06 & -0.06 & -0.06 & -0.06 & -0.06 & -0.07 & -0.07 & -0.07 & $-0.29^{*}$ & -0.21 & $-0.29^{*}$ & -0.21 & 0.78 & 0.31 & 0.78 & 0.31 & 0.02 & 0.02 & 0.02 & 0.02 \\
\hline$d_{2}$ & 0.13 & 0.13 & 0.13 & 0.13 & $0.16^{\dagger}$ & 0.16 & $0.17^{*}$ & 0.17 & $0.41^{* *}$ & 0.28 & $0.41^{* *}$ & 0.28 & 0.18 & 0.07 & 0.18 & 0.07 & 0.03 & 0.02 & 0.03 & 0.02 \\
\hline$d_{3}$ & 0.06 & 0.09 & 0.06 & 0.09 & 0.05 & 0.06 & 0.04 & 0.05 & 0.06 & 0.05 & 0.06 & 0.05 & $0.36^{\dagger}$ & 0.17 & $0.36^{\dagger}$ & 0.17 & -0.04 & -0.05 & -0.04 & -0.05 \\
\hline$d_{4}$ & -0.06 & -0.09 & -0.06 & -0.09 & -0.06 & -0.13 & $-0.07^{\dagger}$ & -0.14 & -0.09 & -0.13 & -0.09 & -0.12 & 0.15 & 0.08 & 0.15 & 0.08 & -0.08 & -0.09 & -0.08 & -0.10 \\
\hline \multicolumn{21}{|l|}{$\begin{array}{l}\text { Lagged effects } \\
\text { of ascribed PA } \\
\text { on behaviors }\end{array}$} \\
\hline$e_{1}$ & & & $\mathrm{n} / \mathrm{a}$ & & & & $0.38^{*}$ & 0.18 & & & 0.08 & 0.07 & & & -0.04 & -0.12 & & & 0.02 & 0.0 \\
\hline$e_{2}$ & & & 0.14 & 0.08 & & & -0.11 & -0.06 & & & -0.03 & -0.03 & & & 0.05 & 0.08 & & & -0.12 & -0.1 \\
\hline$e_{3}$ & & & $-0.26^{\dagger}$ & -0.14 & & & $\mathrm{n} / \mathrm{a}$ & & & & $\mathrm{n} / \mathrm{a}$ & & & & $\mathrm{n} / \mathrm{a}$ & & & & 0.05 & 0.03 \\
\hline$e_{4}$ & & & 0.15 & 0.08 & & & -0.09 & -0.04 & & & 0.04 & 0.02 & & & 0.03 & 0.05 & & & $\begin{array}{c}0.22^{\dagger} \\
-\end{array}$ & 0.16 \\
\hline$e_{5}$ & & & 0.04 & 0.11 & & & $0.15^{*}$ & 0.20 & & & 0.16 & 0.24 & & & -0.01 & -0.09 & & & $0.12^{* *}$ & -0.2 \\
\hline
\end{tabular}

Note. For the interpretation of the path coefficients $a_{1}$ to $d_{4}$ see Figure 1 . The three spouse-directed behaviors during the separation scene were not included in the

respective path models because of their low frequencies (see Table 1). For these variables, the path coefficient $a_{3}$ reflects the autoregressive association of each variable between the all-together scene and the reunion scene (instead of between the separation scene and the reunion scene), the path coefficient $d_{3}$ reflects the lagged effect of these variables measured during the all-together scene (instead of during the separation scene) on ascribed loneliness immediately after the reunion, and the paths $a_{2}$ and $c_{3}$ are not modeled. The frequency of interactions with others was not measured during the dyad scene. For this variable, the paths $a_{1}$ and $c_{1}$ are not modeled. The path coefficients $e_{1}$ to $e_{5}$ are not depicted in Figure 1 . They reflect the association between ascribed affect (PA) and social 
behaviors between intro and dyad scene ( $e_{1}$, cf. $c_{1}$ in Figure 1), between intro and all-together scene $\left(e_{2}, \mathrm{cf} . c_{2}\right.$ in Figure 1), within the separation scene $\left(e_{3}\right.$, cf. $c_{3}$ in Figure 1), within the reunion scene ( $e_{4}$, cf. $c_{4}$ in Figure 1), and within the outro scene $\left(e_{5}\right.$, cf. $c_{5}$ in Figure 1). ${ }^{* * *} p<.001,{ }^{* *} p<.01,{ }^{*} p<.05,{ }^{\dagger} p<.10 . B=$ unstandardized path coefficient, $\beta=$ standardized path coefficient, $\mathrm{n} / \mathrm{a}=$ not applicable. 


\section{Figure captions}

Figure 1. Sequence of Simoland scenes and events and the general path model used to analyze the data. The average frequency of spouse-directed behaviors (overall frequency of interactions with spouse, frequency of affectionate behaviors, frequency of provocative behaviors) during the separation scene was close to zero and therefore not included in the path models. Paths $a_{2}$ and $c_{3}$ were therefore not included in the path models for these behavioral variables. In addition, for these variables, the path $a_{3}$ reflects their association between the alltogether scene and the reunion scene; and the path $d_{3}$ reflects the effect of spouse-directed behaviors during the all-together scene on ascribed loneliness at the beginning of the reunion scene. Similarly, the frequency of social interactions with other (non-spousal) characters was not measured during the dyad scene. Paths $a_{1}$ and $c_{1}$ were therefore not included in the path model for this behavioral variable. 


\section{Supplemental Material}

Table S1. Categorization of Simoland behaviors.

\begin{tabular}{|c|c|c|c|c|c|}
\hline Behavior & $\begin{array}{l}\text { Solitary } \\
\text { activities }\end{array}$ & $\begin{array}{c}\text { Social } \\
\text { interactions } \\
\text { with spouse }\end{array}$ & $\begin{array}{c}\text { Social } \\
\text { interactions } \\
\text { with others }\end{array}$ & $\begin{array}{c}\text { Affectionate } \\
\text { behaviors }\end{array}$ & $\begin{array}{c}\text { Provocative } \\
\text { behaviors }\end{array}$ \\
\hline \multicolumn{6}{|l|}{ Solitary activities } \\
\hline Sleep & $x$ & & & & \\
\hline Meditate & $x$ & & & & \\
\hline Listen to music: Classic & $x$ & & & & \\
\hline Listen to music: Rock & $x$ & & & & \\
\hline Listen to music: Jazz & $x$ & & & & \\
\hline Listen to music: Techno & $x$ & & & & \\
\hline Paint & $x$ & & & & \\
\hline \multicolumn{6}{|l|}{ Conversations } \\
\hline $\begin{array}{l}\text { Talk about hobbies } \\
\text { Talk about how one is }\end{array}$ & & $x$ & $x$ & & \\
\hline doing & & $x$ & $x$ & & \\
\hline Talk about relationship & & $x$ & $x$ & & \\
\hline $\begin{array}{l}\text { Talk about career successes } \\
\text { Say 'Tell me how you're }\end{array}$ & & $x$ & $x$ & & \\
\hline $\begin{array}{l}\text { doing!' } \\
\text { Talk about latest events }\end{array}$ & & $x$ & $x$ & & \\
\hline \multicolumn{6}{|l|}{ Look for comfort } \\
\hline \multicolumn{6}{|l|}{ Shared activities } \\
\hline Listen to music together & & $x$ & $x$ & & \\
\hline \multicolumn{6}{|l|}{$\begin{array}{l}\text { Activities related to closeness } \\
\text { and distance }\end{array}$} \\
\hline Say: 'I need some distance' & & $x$ & $x$ & & \\
\hline Call spouse & & $x$ & $x$ & & \\
\hline \multicolumn{6}{|l|}{ Conflict } \\
\hline $\begin{array}{l}\text { Tease } \\
\text { Begin fight } \\
\text { Insult } \\
\text { Criticize } \\
\text { Ridicule }\end{array}$ & & $x$ & $x$ & & $x$ \\
\hline Affectionate behaviors & & & & & \\
\hline Make a compliment* & & $x$ & $x$ & $x$ & $x$ \\
\hline I love you!* & & $x$ & $x$ & $x$ & $x$ \\
\hline
\end{tabular}


Cuddling*

Make out*

Kiss*

Flirting*

Talk about getting married

Talk about wishes/life goals

Have a family

Climb a mountain

Be successful and rich

Love that lasts a lifetime

Find soulmate

Make a world trip on your own

Eat

Drink

Interactions with absent

spouse

Show on screen

Think about spouse

Write letter to spouse

Call spouse $\times \quad \times \quad x \quad x$

$x \quad x \quad x \quad x$

$x \quad x$

$\times \quad x$

$x \quad x$

$\times \quad \times$

$\times$

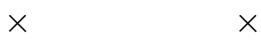

$x \quad x$

$\times \quad \times$

$\times \quad x$

$\times \quad \times$

$\times \quad \times$

Notes. * These behaviors counted as affectionate behaviors if they were directed toward the spouse and as provocative behaviors if they were directed toward other Simos (i.e., cheating on spouse). 
Table S2. Correlations of ascribed loneliness and ascribed positive affect with all behavioral variables.

\begin{tabular}{|c|c|c|c|c|c|c|c|c|c|c|c|}
\hline & Variable & 1 & 2 & 3 & 4 & 5 & 6 & 7 & 8 & 9 & 10 \\
\hline 1 & Ascribed loneliness Intro & -- & & & & & & & & & \\
\hline 2 & Ascribed loneliness All Together & .01 & -- & & & & & & & & \\
\hline 3 & Ascribed loneliness Separation & .30 & .08 & -- & & & & & & & \\
\hline 4 & Ascribed loneliness Reunion & .06 & .34 & .06 & -- & & & & & & \\
\hline 5 & Ascribed loneliness Outro & -.05 & .33 & .01 & .51 & -- & & & & & \\
\hline 6 & Ascribed PA Intro & -.44 & -.13 & -.10 & -.29 & -.29 & -- & & & & \\
\hline 7 & Ascribed PA All Together & -.01 & -.66 & -.07 & -.46 & -.47 & .34 & -- & & & \\
\hline 8 & Ascribed PA Separation & -.41 & -.09 & -.64 & -.23 & -.16 & .29 & .17 & -- & & \\
\hline 9 & Ascribed PA Reunion & -.07 & -.36 & -.08 & -.83 & -.56 & .33 & .52 & .22 & -- & \\
\hline 10 & Ascribed PA Outro & .06 & -.30 & -.02 & -.55 & -.85 & .31 & .47 & .19 & .59 & -- \\
\hline 11 & Solitary activities Intro & .24 & -.05 & .11 & .07 & .02 & .11 & .21 & -.16 & -.02 & .01 \\
\hline 12 & Solitary activities Dyad & .03 & -.02 & .03 & .03 & .09 & .04 & .05 & -.15 & .04 & -.03 \\
\hline 13 & Solitary activities All Together & .01 & .00 & .09 & .04 & .09 & -.07 & -.04 & -.13 & -.03 & -.07 \\
\hline 14 & Solitary activities Separation & .00 & -.10 & .03 & .00 & -.07 & -.03 & .01 & -.04 & .04 & .01 \\
\hline 15 & Solitary activities Reunion & -.09 & -.09 & .01 & -.08 & -.13 & .07 & .10 & -.08 & .12 & .10 \\
\hline 16 & $\begin{array}{l}\text { Solitary activities Outro } \\
\text { Interactions with others All }\end{array}$ & .14 & .07 & -.03 & .09 & -.16 & .02 & .02 & -.05 & -.04 & .06 \\
\hline 17 & Together & .12 & -.03 & .11 & -.04 & -.11 & .05 & .14 & -.19 & .03 & .18 \\
\hline 18 & Interactions with others Separation & .16 & .01 & .05 & .05 & -.10 & -.04 & .06 & -.14 & -.03 & .04 \\
\hline 19 & Interactions with others Reunion & .22 & .04 & .09 & .09 & -.02 & -.06 & .09 & -.13 & -.06 & .04 \\
\hline 20 & Interactions with others Outro & .00 & -.20 & .02 & -.06 & -.11 & .11 & .16 & -.09 & .21 & .12 \\
\hline 21 & $\begin{array}{l}\text { Interactions with spouse Dyad } \\
\text { Interactions with spouse All }\end{array}$ & .23 & -.11 & .19 & -.13 & -.15 & .00 & .17 & -.09 & .11 & .16 \\
\hline 22 & Together & .24 & -.14 & .11 & .07 & -.13 & -.13 & .11 & -.13 & -.01 & .04 \\
\hline 23 & Interactions with spouse Separation & .08 & -.04 & .09 & .00 & .06 & -.15 & -.03 & -.11 & .04 & -.03 \\
\hline 24 & Interactions with spouse Reunion & .23 & -.24 & .17 & -.27 & -.26 & .04 & .21 & -.11 & .24 & .22 \\
\hline 25 & Interactions with spouse Outro & .17 & .01 & .09 & -.17 & -.11 & -.04 & .09 & -.01 & .09 & .15 \\
\hline 26 & Provocative behaviors Dyad & .02 & .05 & -.01 & .04 & .14 & -.08 & -.07 & -.11 & -.11 & -.09 \\
\hline 27 & Provocative behaviors All Together & -.02 & .27 & .08 & .20 & .07 & .04 & -.13 & -.06 & -.15 & -.03 \\
\hline 28 & Provocative behaviors Separation & .10 & .14 & .06 & .19 & .03 & -.09 & -.10 & -.16 & -.17 & -.11 \\
\hline
\end{tabular}




\begin{tabular}{|c|c|c|c|c|c|c|c|c|c|c|c|}
\hline 29 & Provocative behaviors Reunion & .14 & .20 & .11 & .22 & .19 & -.04 & -.15 & -.17 & -.23 & -.13 \\
\hline 30 & Provocative behaviors Outro & .07 & -.08 & -.01 & .08 & -.03 & -.06 & .10 & .04 & -.06 & .00 \\
\hline 31 & Affectionate behaviors Dyad & .08 & -.04 & .09 & -.03 & -.01 & -.02 & .07 & -.09 & .03 & .07 \\
\hline 32 & Affectionate behaviors All Together & .30 & -.24 & .22 & .02 & -.12 & -.10 & .18 & -.24 & .06 & .06 \\
\hline 33 & Affectionate behaviors Separation & .08 & -.04 & .09 & .00 & .06 & -.15 & -.03 & -.11 & .04 & -.03 \\
\hline 34 & Affectionate behaviors Reunion & .27 & -.23 & .14 & -.25 & -.24 & -.02 & .23 & -.13 & .24 & .21 \\
\hline 35 & Affectionate behaviors Outro & .25 & -.06 & .18 & -.11 & -.08 & -.04 & .05 & -.10 & .04 & .13 \\
\hline
\end{tabular}


Table S3. Correlations among all behavioral variables. .

\begin{tabular}{|c|c|c|c|c|c|c|c|c|c|c|c|c|c|c|c|c|c|c|c|c|c|c|c|c|c|}
\hline & Variables & 1 & 2 & 3 & 4 & 5 & 6 & 7 & 8 & 9 & 10 & 11 & 12 & 13 & 14 & 15 & 16 & 17 & 18 & 19 & 20 & 21 & 22 & 23 & 24 \\
\hline 1 & $\begin{array}{c}\text { Solitary } \\
\text { activities } \\
\text { Intro }\end{array}$ & -- & & & & & & & & & & & & & & & & & & & & & & & \\
\hline 2 & $\begin{array}{c}\text { Solitary } \\
\text { activities } \\
\text { Dyad } \\
\text { Solitary }\end{array}$ & .14 & -- & & & & & & & & & & & & & & & & & & & & & & \\
\hline 3 & $\begin{array}{l}\text { activities All } \\
\text { Together } \\
\text { Solitary }\end{array}$ & -.04 & .12 & -- & & & & & & & & & & & & & & & & & & & & & \\
\hline 4 & $\begin{array}{l}\text { activities } \\
\text { Separation }\end{array}$ & .00 & -.12 & .20 & -- & & & & & & & & & & & & & & & & & & & & \\
\hline 5 & $\begin{array}{l}\text { Solitary } \\
\text { activities } \\
\text { Reunion }\end{array}$ & .07 & .19 & .20 & .17 & -- & & & & & & & & & & & & & & & & & & & \\
\hline 6 & $\begin{array}{l}\text { Solitary } \\
\text { activities } \\
\text { Outro }\end{array}$ & .04 & -.02 & .01 & -.06 & .06 & -- & & & & & & & & & & & & & & & & & & \\
\hline 7 & $\begin{array}{l}\text { Interactions } \\
\text { with others } \\
\text { All Together }\end{array}$ & .26 & .08 & -.15 & -.06 & .00 & .16 & -- & & & & & & & & & & & & & & & & & \\
\hline 8 & $\begin{array}{l}\text { Interactions } \\
\text { with others } \\
\text { Separation }\end{array}$ & .19 & .21 & .00 & -.39 & .05 & .14 & .40 & -- & & & & & & & & & & & & & & & & \\
\hline 9 & $\begin{array}{l}\text { Interactions } \\
\text { with others } \\
\text { Reunion }\end{array}$ & .20 & .21 & .10 & -.05 & -.13 & .12 & .31 & .35 & -- & & & & & & & & & & & & & & & \\
\hline 10 & $\begin{array}{l}\text { Interactions } \\
\text { with others } \\
\text { Outro }\end{array}$ & .07 & .05 & -.01 & -.01 & .07 & -.10 & .19 & .06 & .00 & -- & & & & & & & & & & & & & & \\
\hline 11 & $\begin{array}{l}\text { Interactions } \\
\text { with spouse } \\
\text { Dyad }\end{array}$ & .35 & -.21 & .01 & .06 & -.08 & .05 & .53 & .31 & .25 & .17 & -- & & & & & & & & & & & & & \\
\hline 12 & $\begin{array}{l}\text { Interactions } \\
\text { with spouse } \\
\text { All Together }\end{array}$ & .19 & .01 & -.03 & .11 & .16 & -.03 & -.11 & .21 & .06 & .01 & .17 & -- & & & & & & & & & & & & \\
\hline 13 & $\begin{array}{l}\text { Interactions } \\
\text { with spouse } \\
\text { Separation }\end{array}$ & .06 & .02 & -.07 & -.09 & .13 & -.05 & .01 & .05 & .02 & -.04 & -.01 & -.02 & -- & & & & & & & & & & & \\
\hline 14 & $\begin{array}{l}\text { Interactions } \\
\text { with spouse }\end{array}$ & .24 & -.07 & -.04 & .09 & -.07 & .04 & .21 & .29 & -.02 & .16 & .48 & .35 & -.02 & -- & & & & & & & & & & \\
\hline
\end{tabular}


Reunion

Interactions

with spouse

Outro

Provocative

16 behavior

Provocative

17 behaviors All

Together

Provocative

18 behavior

Separation

Provocative

behaviors

Reunion

Provocative

Outrors

Affectionate

behaviors

Dyad

Affectionate

behaviors All

Together

Affectionate

behaviors
Separation

Affectionate

$\begin{array}{lllllllllllllll}.02 & -.02 & .00 & .06 & -.01 & -.23 & .15 & .16 & .13 & -.32 & .27 & .32 & .02 & .37 & --\end{array}$

$\begin{array}{lllllllllllllllll}.17 & .07 & .12 & -.14 & .14 & .04 & .09 & .11 & .03 & .18 & .10 & -.10 & .19 & -.13 & -.14 & --\end{array}$

$\begin{array}{lllllllllllllllll}.00 & .10 & .02 & -.12 & .01 & .12 & .28 & .21 & .22 & -.14 & .08 & -.01 & -.03 & -.17 & .04 & .03 & --\end{array}$

$\begin{array}{llllllllllllllllll}.03 & .18 & -.01 & -.16 & -.01 & .10 & .23 & .45 & .33 & .05 & .02 & .16 & -.02 & -.06 & .03 & .05 & .47 & --\end{array}$

$\begin{array}{llllllllllllllllllll}.11 & .12 & .07 & -.07 & -.08 & .14 & .12 & .18 & .46 & .05 & .07 & .11 & -.02 & -.08 & -.06 & .12 & .21 & .30 & --\end{array}$

$\begin{array}{llllllllllllllllllllll}.05 & .14 & .06 & .05 & .04 & -.11 & -.03 & .17 & .12 & .16 & .03 & .29 & -.02 & .06 & .01 & .05 & .00 & .28 & .14 & --\end{array}$

$\begin{array}{lllllllllllllllllllllll}.27 & -.05 & .03 & -.05 & -.01 & .02 & .32 & .15 & .15 & .09 & .66 & .02 & .04 & .23 & .18 & .07 & .01 & -.06 & -.01 & -.01 & --\end{array}$

$\begin{array}{llllllllllllllllllllllll}.28 & .04 & -.05 & .08 & .10 & .10 & .11 & .32 & .08 & .00 & .32 & .78 & .03 & .45 & .30 & -.07 & -.10 & .12 & .09 & .26 & .14 & --\end{array}$

$\begin{array}{llllllllllllllllllllllllllll}.06 & .02 & -.07 & -.09 & .13 & -.05 & .01 & .05 & .02 & -.04 & -.01 & -.02 & 1.0 & -.02 & .02 & .19 & -.03 & -.02 & -.02 & -.02 & .04 & .03 & --\end{array}$

24 behaviors

Reunion

$\begin{array}{llllllllllllllllllllllllll}.22 & -.03 & -.04 & .01 & .04 & -.04 & .21 & .31 & .02 & .11 & .41 & .26 & .00 & .77 & .34 & -.14 & -.12 & -.04 & -.15 & .05 & .25 & .40 & .00 & --\end{array}$

Affectionate

25 behaviors Outro 
Table S4. Means and standard deviations for credibility questions.

\begin{tabular}{|c|c|c|c|}
\hline Item & $M$ & $S D$ & $\begin{array}{l}\text { Correlation with } \\
\text { subject loneliness }\end{array}$ \\
\hline In hindsight: Did you choose behaviors that you would have chosen in real life as well? & 3.13 & 0.70 & -0.08 \\
\hline Did you try things that you would never have done in real life? & 1.13 & 1.01 & 0.16 \\
\hline Did you choose behaviors that you would like to try in real life? & 2.06 & 1.20 & 0.11 \\
\hline I identified with the protagonist. & 2.59 & 1.03 & -0.05 \\
\hline I thought the game was ridiculous . & 1.32 & 1.01 & 0.03 \\
\hline I was always aware that the other characters were computer-controlled. & 2.70 & 1.21 & -0.07 \\
\hline I was completely engaged in the game. & 3.09 & 0.86 & -0.12 \\
\hline I often thought that these are only computer characters. & 1.41 & 1.08 & -0.05 \\
\hline
\end{tabular}

Note. Response format for all items ranged from 0 (not at all) to 4 (very). 